\title{
On the prospective contributions of the shock physics community to outstanding issues concerning blast-induced traumatic brain injury
}

\author{
S. Ouellet ${ }^{1}$ - O. E. Petel ${ }^{2}$
}

Published online: 15 November 2017

(C) Her Majesty the Queen in Right of Canada, as represented by the Minister of National Defence, 2017

\section{Overview}

The task of understanding, predicting, and ultimately mitigating blast-induced traumatic brain injury (bTBI) requires a broad-based multidisciplinary approach, integrating synergistic contributions from distinct scientific communities that do not historically collaborate. For example, in the field of injury biomechanics, experimental work involving animal models or cadaveric specimens is often considered to be the gold standard; however, only a limited number of shock wave research laboratories have the requisite biosafety or access to cadaveric specimens. As these studies are of critical importance to the understanding of the biological effects of blast exposure and to the development of injury criteria that will be incorporated into injury prevention and mitigation strategies, it would appear natural to have this type of work to be led by the biomedical research community. Rigorous preparation, execution, and analysis of animal and cadaveric experiments require a particular knowledge set that is often lacking in the engineering or physics community.

On the other hand, the lack of appreciation of blast physics from the biomedical research community may have led to supplementary confusion surrounding the injury mechanisms involved in bTBI $[1,2]$. The interaction between a blast wave originating from an explosion and the human head and body structure is a complex, multifaceted problem that can be unintentionally biased. Methodological inconsistencies in the reproduction of relevant blast exposure conditions

S. Ouellet

simon.ouellet@drdc-rddc.gc.ca

1 Defence Research and Development Canada - Valcartier Research Center, Quebec, QC G2C 1X5, Canada

2 Department of Mechanical and Aerospace Engineering, Carleton University, Ottawa, ON K1S 5B6, Canada are recognized as an ongoing concern in the published literature on bTBI. There are multiple factors that can lead to the observed methodological inconsistencies, the majority of which appears to be linked either to a poor definition of the problem space, a misunderstanding of the effect of scale, or to an inadequate design of laboratory experiments. The primary objective of the bTBI thematic issue is to engage the broader shock physics research community to tackle the currently intractable aspects of bTBI research outlined below.

\subsection{Relevant exposure and loading conditions}

Publicly available information on the military operational and training threat environment is rare. This can be attributed to obvious security concerns as well as the variability in explosive threats such as improvised explosive devices (IEDs). While epidemiological data and injury trends from recent military conflicts are available from multiple sources [3-5], detailed information regarding relevant operational threat scenarios is harder to come by. In the absence of such information, a majority of experimentalists and modellers are forced to make educated guesses on the type of blast conditions they feel to be representative of real-life scenarios. An additional complication is that the range of blast parameters relevant to the generation of bTBI in humans is still not definitive. This situation leads to difficulties in setting meaningful bounds to the bTBI problem, resulting in a field of literature obscured by a spectrum of studies using overaggressive or benign loading conditions. To appropriately study bTBI, loading conditions should be bound by the intersection of operational relevancy, injury risk potential for bTBI, and the likelihood of survivability with regard to the other injury threats (e.g., fragmentation). 
Fig. 1 Illustration of the size of the bTBI problem space in the peak incident overpressure-positive phase duration plane. Inset: Schematic of a Friedlander waveform

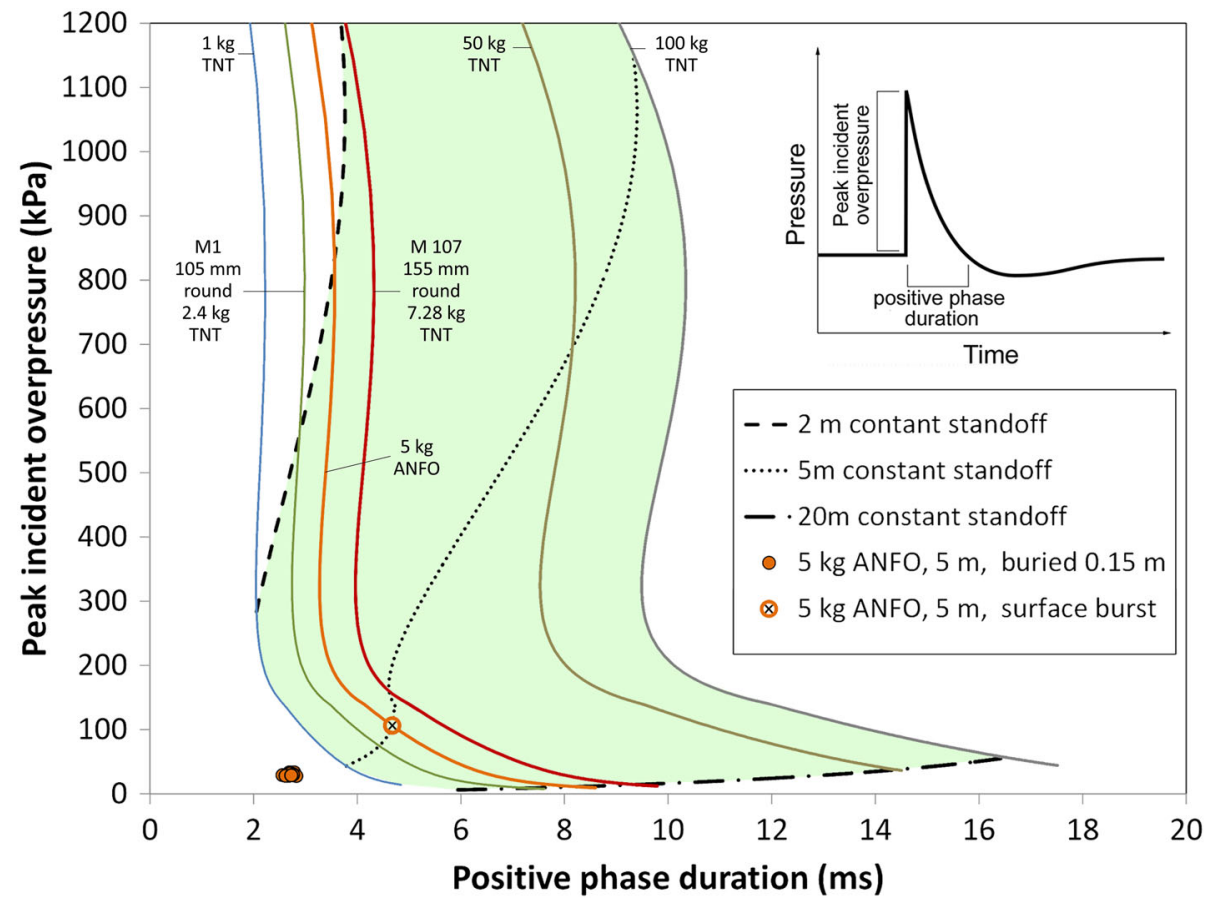

For simplicity, the vast majority of researchers have approached the study of bTBI focused on the basic case of free-field, perpendicular exposure to a planar blast wave, where the blast wave may be described as an idealized Friedlander wave. Realistic threat scenarios may include above-ground detonation in the near- to mid-field, buried explosive charges in different soil conditions or complex blast waves from explosions in the vicinity of reflecting structures; these configurations further complicate an already complex problem. Despite the focus on this simpler free-field loading scenario, few researchers justify their choice of free-field exposure conditions using estimated real operational scenarios, which is necessary to maintain relevance. One example of an appropriate justification is the use of a report on 18 incident cases from operation Iraqi Freedom [6] to guide the choice of loading conditions [7]. Panzer et al. [7] used the ground detonation of standard 105 and $155 \mathrm{~mm}$ artillery rounds as classic IED scenarios and used the CONWEP software [8] to predict peak incident overpressure and positive phase duration for standoff distances varying between 1 and $5 \mathrm{~m}$, leading to peak overpressures ranging from 50 to $1000 \mathrm{kPa}$ and durations between 2 and $6 \mathrm{~ms}$. Wood et al. [9] further stated that $a$ majority of IED threats are made from artillery rounds equivalent to $7.5 \mathrm{~kg}$ of TNT explosives or less. Shridhanari et al. [10] included a $50 \mathrm{~kg}$ of TNT equivalent at 7-10 $\mathrm{m}$ to be representative of a vehicle-borne IED. They simulated scenarios including blast waves with peak overpressures between 110 and $740 \mathrm{kPa}$ with durations between 1.3 and $6.9 \mathrm{~ms}$. Varas et al. [11] reported peak overpressure and duration data from alleged IED experiments and stated that the ranges of peak overpressure between 10 and $200 \mathrm{kPa}$ and positive phase durations between 4 and $10 \mathrm{~ms}$ are relevant to a military IED scenario. In a response to Nyein et al. [12], who had chosen a very close exposure to a 3.16-g TNT charge to simulate a blast threat, Moss et al. [13] mentioned that $2.2 \mathrm{~kg}$ of TNT was a more relevant military threat. Rafaels et al. [14] stated that relevant scenarios including terrorist attacks may consist in the explosion of $1-800 \mathrm{~kg}$ of TNT equivalent, at various distances. Sundaramurthy et al. [15] chose a range of conditions, based on various sources, using $\mathrm{C} 4$ explosives between 1 and $100 \mathrm{~kg}$ and standoff distances between 2 and $10 \mathrm{~m}$ to represent operational scenarios, which yielded peak overpressures between 60 and $450 \mathrm{kPa}$ and a range of duration between 2 and $8 \mathrm{~ms}$. It appears clear that the range of threat considered to be relevant is very large. For illustration purposes, the space bounded by the detonation of $1 \mathrm{~kg}$ of TNT equivalent between 2 and $20 \mathrm{~m}$ and $100 \mathrm{~kg}$ of TNT equivalent between 2 and $20 \mathrm{~m}$ is presented in Fig. 1 as a plot of peak incident overpressure as a function of positive phase duration using the blast parameter relationship developed by Kingery and Bulmash [16]. As a reference, the peak overpressure vs. duration relationship for a M1 $105 \mathrm{~mm}$ artillery munition and a $155 \mathrm{~m} \mathrm{M} 107$ munition is also plotted on the graph. Because of its apparent relevance to IED scenarios, curves are also shown for 5 of ANFO explosives. An example of a recent pressure measurement made during the explosion of $5 \mathrm{~kg}$ of ANFO explosive buried $0.15 \mathrm{~m}$ into $0-9.5 \mathrm{~mm}$ gravel is shown to highlight the considerable difference in overpressure signature compared to a surface burst. 
Fig. 2 Reduction of the bTBI problem space using injury risk functions for fatality and mild bleeding in the brain (adapted from [14]) as the upper and lower bound

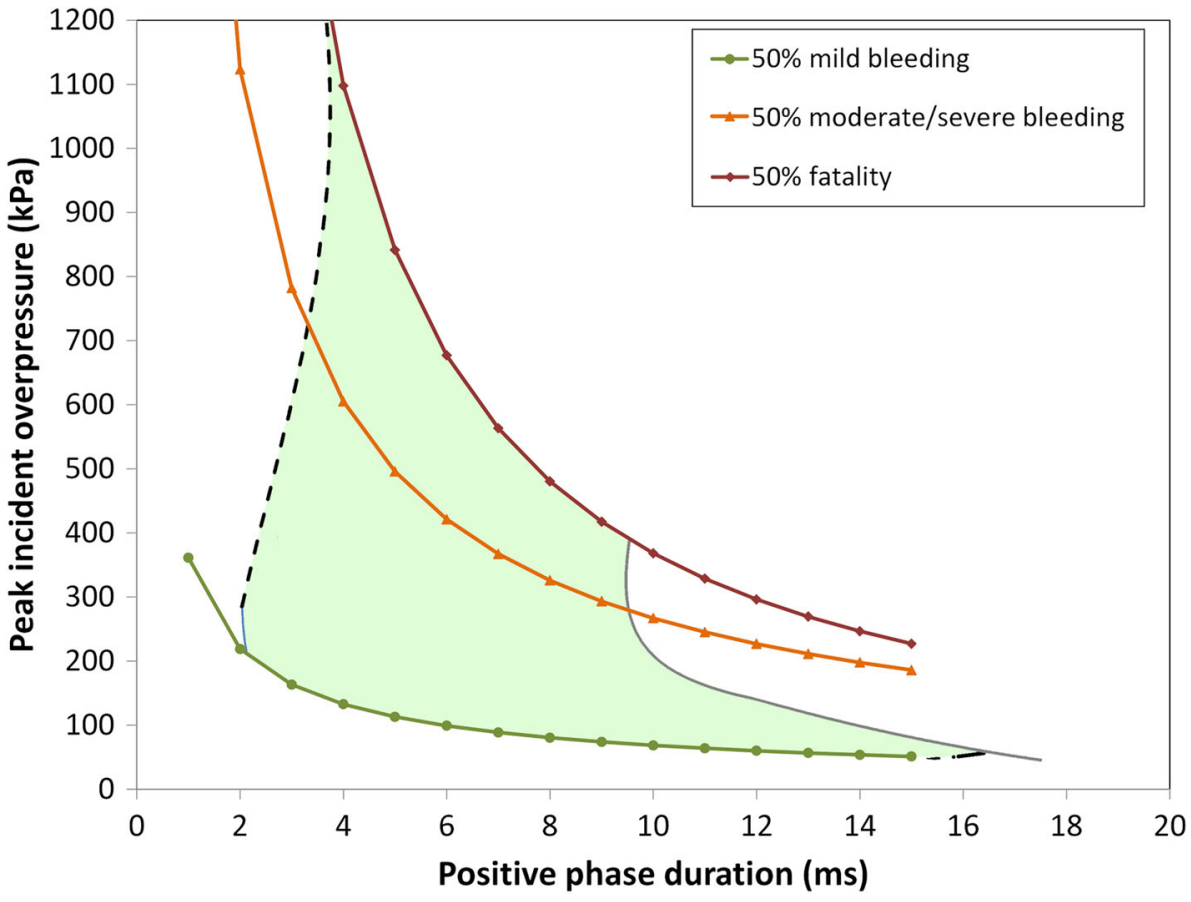

The range of possible exposure conditions is large and likely encompasses multiple regimes of response of the human body. The evolution of the transient pressure field (i.e., target loading) that develops around the head as the blast wave diffracts around it will not be the same across this domain of possible conditions. To understand and interpret the response of living organisms to such a wide range of stimuli, it is critical to understand the nature and specificities of the loading experienced by the subject. This is a classic shock wave diffraction problem that is further complicated if we consider non-ideal scenarios such as non-perpendicular reflection (head exposed to wave from surface burst), buried explosive charges, and a non-planar and a non-uniform wave in the near field. This is precisely where further input from the shock physics community may contribute to the field.

Operationally, many of the above conditions are tied to explosive events where other types of blast injuries could dominate the injury spectrum, such as high-energy fragmentation injury or thoracic primary blast injuries. The lethal radius of fragments generated from the explosion of standard artillery rounds exceeds by an order of magnitude that of primary blast injuries [17]. While these notions could help further limit the problem space for bTBI, the development of high-performance personal protective equipment (PPE) makes a considerable difference in defeating ballistic threats as well as significantly increasing the injury thresholds for primary blast injury to the lung [18]. As such, it is more conservative not to further limit the problem space based on other threats, which may or may not be survivable.

\subsection{Injury risk and injury thresholds}

In contrast to the existing body of work defining injury criteria (injury risk functions) for thoracic primary blast injuries [19-24], studies addressing the definition of injury risk functions for blast TBI applicable to humans are very limited $[14,25,26]$. Shock tube experiments involving rabbits [25] and ferrets [14] were used by Rafaels et al. to propose injury functions from linear logistic regressions for the risk of mild bleeding, moderate to severe bleeding, and fatality. Although it was recognized that common scaling approaches may not apply to brain blast injury, the functions were scaled to a 70-kg man using a mass scaling approach similar to that used previously by Bowen et al. [19] in the study of other blast injuries. Other research has investigated injury thresholds using animal models [27,28], but these efforts did not address how the criteria could scale to humans. Notwithstanding the validity of the proposed injury risk functions, it is important to consider the value of this type of information for further reducing the bTBI problem space. As an example, the $50 \%$ risk curves for mild bleeding, moderate to severe bleeding, and fatality from Rafaels et al. are overlaid on the graph of Fig. 1 (see Fig. 2). Although this exercise significantly reduces the bTBI problem space, the range of relevant conditions of interest is still quite large.

\subsection{Scaling}

Aside from defining a relevant problem space, much of the experimental work in the field involves animal mod- 
els. Therefore, blast parameter scaling for bTBI studies using animal models is an important aspect of the problem. Scaling is the basis through which injury thresholds and risk assessments are established for humans. The limited amount of research on bTBI across a range of different species has prevented the establishment of robust scaling laws that would allow extrapolation to humans. Owing to its successful use for thoracic primary blast injuries and for automotive blunt impacts, scaling based on body weight ratio has been proposed for bTBI $[2,14,24,29]$. It has, however, been acknowledged that the scaling approach should be based on head/brain-specific anatomical and physiological considerations [2,30,31]. Skull-based metrics, such as skull principal dimensions and thickness, thickness of cerebrospinal fluid (CSF) space, brain mass, or more specific neuroanatomical features may provide better options to account for the morphological differences between species. Jean et al. [31] proposed an animal-to-human scaling law based on wave propagation dimensional arguments. The new scaling method yielded results that are in stark contrast with classical mass scaling approaches, suggesting that the human brain is more vulnerable to blast than the brain of a mouse. Although the fundamentals of bTBI scaling across species remain misunderstood, there are strong arguments in favour of the use of scaling laws. However, it is unfortunately not standard practice. While few researchers have purposely designed experiments to generate scaled-down exposure conditions $[14,32,33]$ against small mammals, others expose animal models to blast parameters relevant to humans [27,34-43]. Assuming mass scaling is relevant to bTBI, some of these exposures may effectively result in exposing an animal model to nuclear-sized blasts [29].

A bTBI scaling law would ideally be based on the mechanism of injury. Unfortunately, there is still a great amount of debate with regard to potential injury mechanisms contributing to the generation of neuropathology following blast exposure [44]. Further complications inherent in defining a dominant injury mechanism in bTBI are that various proposed mechanisms may not be mutually exclusive. Nevertheless, external and internal wave mechanics undeniably play an important role in the biomechanical response of the head and brain. The establishment of robust scaling laws requires rigorous wave-mechanics treatment and the valuable input from the shock physics community.

\subsection{Reproducing blast exposure in a laboratory environment}

The limited availability of test ranges where full-scale explosive testing can be conducted, along with requirements to control exposure conditions and ensure reproducibility, has led multiple researchers to choose shock tubes as their preferred option for producing shock loading in the laboratory environment. However, several aspects of shock tube testing are often overlooked, with the consequence of bringing additional confusion to the field. Needham et al. [2] provided a very comprehensive description of some of the common misuses and misconceptions regarding conventional shock tubes. Among other aspects, the testing of biological models is sensitive to any loading artefacts that may follow the initial loading phase. Rarefaction waves entering the tube from the open end and reaching the target after the initial overpressure loading should be accounted for or eliminated. Also, the use of the shock tube end jet to generate a decaying blast profile has been a popular approach $[36,40,45]$, but such a set-up neglects that the blast flow field and ensuing dynamic pressure loading on the target are drastically changed even though the incident overpressure history may appear to match free-field scenarios. Another issue with conventional shock tube testing, which can alter the blast flow field significantly and exaggerate the loading on the target, is the ratio of tube blockage. In order to simulate open-field exposure, the target should not be affected by or interact with the tube lateral boundaries.

Recently, the awareness of conventional shock tube limitations has grown [37,46]. In addition, an increase in the use of advanced blast simulators (ABS), a shock tube with expanding cross section assembled with an end-wave eliminator, has been observed $[43,47-50]$. ABS are reported to be capable of simulating free-field blast conditions with no loading artefacts. Robust testing methods deviating from realistic field exposure are not necessarily irrelevant. They can serve multiple purposes, but their characteristics need to be understood and their limitations stated to be put to good use. It appears that reproducing field exposure in a laboratory environment or interpreting non-ideal exposures is also a challenge which the shock physics community may help to address.

\section{2 bTBI thematic issue}

The objective of the current issue at the outset of this endeavour was to bring together a broad range of researchers from every corner of the multidisciplinary spectrum investigating this health issue. As stated above, there are a number of outstanding issues from a shock wave physics perspective that require further engagement from the shock physics community to ensure the accuracy of experimental and numerical approaches taken in the literature. Better defining the nature of the exposure conditions, describing the interaction of a blast wave with the body, understanding internal wave mechanics, developing relevant scaling approaches, and refining methods to reproduce blast exposure in a laboratory environment are, among others, topics where input of the community is critically needed. We envisage this thematic issue as an important step in engaging the shock physics com- 
munity. The intention of the thematic issue is to provide the reader with an overview of the current state of operational and occupational threats, numerical models, small-scale models, experimental head-brain surrogates, animal models, and medical perspectives on bTBI.

\subsection{Editorial information on the thematic issue}

The call for papers received incredible support from the research community with a total of 26 original research and review manuscripts having been considered for publication. Given the scale of the response received, the thematic issue has been divided into a two-part series, the first covering analytical and computational contributions, while the second focusing primarily on experimental models and investigations of bTBI. The current bTBI thematic issue provides the reader with an overview of the exposure threats that are a contemporary concern as well as a snapshot of the current state-of-the-art in numerical capabilities from leading researchers in the field.

Every contributed article has been subjected to a rigorous peer-reviewed process according to the policies and procedures normally followed by the Shock Waves Journal. Each paper was reviewed by two or more independent referees, each of whom is an internationally recognized expert in the field. Out of 26 submitted manuscripts, two were rejected, four were withdrawn by the authors after a "major revisions" decision, and 18 papers were accepted after, typically, two or three revisions. The present issue (vol. 27, issue 6) contains ten accepted papers, and another eight accepted papers will be published in the next issue (vol. 28, issue 1). The remaining two papers are still in processing and, if eventually accepted, will be included into the next issue or later issues of Shock Waves.

\subsection{Content overview of part 1: modelling and occupational blast exposures}

In the context of the current outlook on bTBI, two manuscripts that provide insightful perspectives into the bTBI issue have been contributed, one from an operational standpoint [51] and the second from a medical perspective [52]. Carr et al. [51] provide a review of several studies focused on human exposure to repeated low-level blast, along with an in-depth discussion of threat characterizations to help guide future research in the area. Kamimori et al. [53] provide experimental data obtained for various occupational blast exposures from breaching operations in varying confinement areas and exposures to military personnel from weapons use. Wiri et al. [54] modelled this threat to determine the pressure distributions on soldier profiles operating shoulder-mounted recoilless weapons. The numerical results of the study are compared to pressure signals measured by blast gauges at specific locations around the weapon during testing. These results will be used to influence training with these weapons in an effort to reduce overpressure exposure to soldiers.

Nakagawa et al. [52] offer a broad overview of knowledge gained from decades of research into shock wave interactions within the body for shock lithotripsy treatments. The contribution from Tripathi et al. [55] provides the framework of a numerical method to describe the propagation and attenuation of shear waves in soft solids, such as tissue simulants. The complexity of the treatment is due to the large discrepancy between the longitudinal and shear wave speeds in tissues. The numerical scheme is validated and compared to experimental shear shock wave propagation in gelatinbased phantoms.

Several articles in this issue investigate the shock wave interactions with the body, each analysing a slightly different system or scale of the problem. Tan et al. [56] developed a numerical model of the entire human body, which was subjected to blast loading from simulated explosions. The whole-body approach to these simulations enables a discussion of the effect of the lungs and torso on the brain response under blast loading, which is found to be non-negligible. Singh and Cronin [57] modelled the effects of the helmet and visor on the load transmission pathways for a blast loading a head model. This work outlines a parametric study varying several helmet features to estimate their influence on head acceleration and intracranial pressures. SarvghadMoghaddam et al. [58] used a detailed finite element model of the head to investigate regions of maximum intracranial pressure, shear stress, and principal strains resulting from blast waves produced by a variation in TNT equivalent explosive masses at a fixed stand-off. These three biomechanical parameters are presented through a series of correlational relationships to linear and angular head accelerations for the three blast intensities considered in an effort to improve the understanding of bTBI injury mechanisms. Haniff et al. [59] focused on the brain at the microscale, examining the interaction between the dynamics of cavitation collapse and axon fibres in close proximity. Cavitation is seeded in their model and perturbed through the application of subsequent pressure pulses, forcing the collapse of blast-induced cavitation bubbles within white matter fibre tracks.

The final paper of the issue involves a numerical and experimental animal model of brain injury. Kalra et al. [60] used a finite element model to investigate open-field blast loading on a pig head model. The numerical model was compared to experimental data with a focus on the intracranial pressure histories at corresponding points.

Acknowledgements The editors would like to thank the authors for their valuable contributions to this thematic issue on a subject matter of tremendous importance. We would like to thank all of the reviewers for committing their time to provide many useful comments and suggestions to improve the manuscripts. A special thanks to Andrew Higgins 
for his tireless efforts and encouragement in pushing our vision for this thematic issue of the journal. Many thanks to Evgeny Timofeev and Harald Kleine for their assistance and guidance in the technical management of the issue.

\section{References}

1. Bass, C.R., Panzer, M.B., Rafaels, K.A., Wood, G., Shridharani, J., Capehart, B.: Brain injuries from blast. Ann. Biomed. Eng. 40(1), 185-202 (2012). doi:10.1007/s10439-011-0424-0

2. Needham, C.E., Ritzel, D., Rule, G.T., Wiri, S., Young, L.: Blast testing issues and TBI: Experimental models that lead to wrong conclusions. Front. Neurol. 6, 72 (2015). doi:10.3389/fneur.2015. 00072

3. Warden, D.: Military TBI during the Iraq and Afghanistan wars. J. Head Trauma Rehabil. 21(5), 398-402 (2006)

4. Owens, B.D., Kragh Jr, J.F., Wenke, J.C., Macaitis, J., Wade, C.E., Holcomb, J.B.: Combat wounds in operation Iraqi Freedom and operation Enduring Freedom. J. Trauma Acute Care Surg. 64(2), 295-299 (2008). doi:10.1097/TA.0b013e318163b875

5. Galarneau, M.R., Woodruff, S.I., Dye, J.L., Mohrle, C.R., Wade, A.L.: Traumatic brain injury during Operation Iraqi Freedom: Findings from the United States Navy-Marine Corps Combat Trauma Registry. Naval Health Research Center Report No. 06-25 (2008)

6. Nelson, T.J., Clark, T., Stedje-Larsen, E.T., Lewis, C.T., Grueskin, J.M., Echols, E.L., Wall, D.B., Felger, E.A., Bohman, H.R.: Close proximity blast injury patterns from improvised explosive devices in Iraq: A report of 18 cases. J. Trauma 65(1), 212-217 (2008). doi:10.1097/01.ta.0000196010.50246.9a

7. Panzer, M.B., Myers, B.S., Capehart, B.P., Bass, C.R.: Development of a finite element model for blast brain injury and the effects of CSF cavitation. Ann. Biomed. Eng. 40(7), 1530-1544 (2012). doi:10.1007/s10439-012-0519-2

8. Hyde, D.: ConWep. Vicksburg, MS: US Army Engineer Research and Development Center (2004)

9. Wood, G.W., Panzer, M.B., Yu, A.W., Rafaels, K.A., Matthews, K.A., Bass, C.R.: Scaling in blast neurotrauma. In: Proceedings of the International Research Council on Biomechanics of Injury, pp. 549-558 (2013)

10. Shridharani, J.K., Wood, G.W., Panzer, M.B., Capehart, B.P., Nyein, M.K., Radovitzky, R.A., Bass, C.R.: Porcine head response to blast. Front. Neurol. 3, 70 (2012). doi:10.3389/fneur.2012.00070

11. Varas, J.M., Philippens, M., Meijer, S.R., van den Berg, A.C., Sibma, P.C., van Bree, J.L.M.J., de Vries, D.V.W.M.: Physics of IED blast shock tube simulations for mTBI research. Front. Neurol. 2, 58 (2011). doi:10.3389/fneur.2011.00058

12. Nyein, M.K., Jason, A.M., Yu, L., Pita, C.M., Joannopoulos, J.D., Moore, D.F., Radovitzky, R.A.: In silico investigation of intracranial blast mitigation with relevance to military traumatic brain injury. Proc. Natl. Acad. Sci. 107(48), 20703-20708 (2010). doi:10. 1073/pnas. 1014786107

13. Moss, W.C., King, M.J., Blackman, E.G.: Distinguishing realistic military blasts from firecrackers in mitigation studies of blastinduced traumatic brain injury. Proc. Natl. Acad. Sci. USA 108, E82 (2011). doi:10.1073/pnas.1101671108

14. Rafaels, K.A., Cameron, R., Panzer, M.B., Salzar, R.S., Woods, W.A., Feldman, S.H., Walilko, T., Kent, R.W., Capehart, B.P., Foster, J.B., Derkunt, B., Toman, A.: Brain injury risk from primary blast. J. Trauma Acute Care Surg. 73(4), 895-901 (2012). doi:10. 1097/TA.0b013e31825a760e

15. Sundaramurthy, A., Chandra, N.: A parametric approach to shape field-relevant blast wave profiles in compressed-gas-driven shock tube. Front. Neurol. 5, 253 (2014). doi:10.3389/fneur.2014.00253
16. Kingery, C.N., Bulmash, G.: Airblast parameters from TNT spherical airburst and hemispherical surface burst. Technical Report ARBRL-TR-02555 (1984)

17. Wood, G.W., Panzer, M.B., Shridharani, J.K., Matthews, K.A., Capehart, B.P., Myers, B.S., Bass, C.R.: Attenuation of blast pressure behind ballistic protective vests. Injury Prev. 19, 19-25 (2013). doi:10.1136/injuryprev-2011-040277

18. Champion, H.R., Holcomb, J.B., Young, L.A.: Injuries from explosions: Physics, biophysics, pathology, and required research focus. J. Trauma Acute Care Surg. 66(5), 1468-1477 (2009). doi:10.1097/ TA.0b013e3181a27e7f

19. Bowen, I.G., Fletcher, E.R., Richmond, D.R.: Estimate of man's tolerance to the direct effects of air blast. Technical Progress Report, DASA-2113, Defense Atomic Support Agency, Department of Defense, Washington, DC, October (1968)

20. Stuhmiller, J.H., Ho, K.H.-H., van der Vorst, M.J., Dodd, K.T., Fitzpatrick, T., Mayorga, M.: A model of blast overpressure injury to the lung. J. Biomech. 29(2), 227-234 (1996). doi:10.1016/ 0021-9290(95)00039-9

21. Axelsson, H., Yelverton, J.T.: Chest wall velocity predictor of nonauditory blast injury in a complex wave environment. J. Trauma Injury Infect. Crit. Care 40(3), 31-37 (1996)

22. Bass, C.R., Rafaels, K.A., Salzar, R.S.: Pulmonary injury risk assessment for short-duration blasts. J. Trauma 65(3), 604-615 (2008). doi:10.1097/TA.0b013e3181454ab4

23. Rafaels, K., Bass, C., Panzer, M.B., Salzar, R.S.: Pulmonary injury risk assessment for long-duration blasts: A metaanalysis. J. Trauma 69(2), 368-374 (2010). doi:10.1097/TA. 0b013e3181e88122

24. Panzer, M.B., Cameron, R., Rafaels, K.A., Shridharani, J., Capehart, B.P.: Primary blast survival and injury risk assessment for repeated blast exposures. J. Trauma Acute Care Surg. 72(2), 454466 (2012). doi:10.1097/TA.0b013e31821e8270

25. Rafaels, K., Bass, C.R., Salzar, R.S., Panzer, M.B., Woods, W., Feldman, S., Cummings, T., Capehart, B.: Survival risk assessment for primary blast exposures to the head. J. Neurotrauma 28(11), 2319-2328 (2011). doi:10.1089/neu.2009.1207

26. Zhu, F., Chou, C.C., Yang, K.H., King, A.I.: Some considerations on the threshold and inter-species scaling law for primary blast-induced traumatic brain injury: A semi-analytical approach. J. Mech. Med. Biol. 13(4), 1350065-1350074 (2013). doi:10.1142/ S0219519413500656

27. Mishra, V., Skotak, M., Shuetz, H., Heller, A., Haorah, J., Chandra, N.: Primary blast causes mild, moderate, severe and lethal TBI with increasing overpressures: Experimental rat injury model. Sci. Rep. 6, 26992 (2016). doi:10.1038/srep26992

28. Courtney, M.W., Courtney, A.C.: Working toward exposure thresholds for blast-induced traumatic brain injury: Thoracic and acceleration mechanisms. Neuroimage 54, S55-S61 (2011). doi:10.1016/ j.neuroimage.2010.05.025

29. Panzer, M.B., Wood, G.W., Bass, C.R.: Scaling in neurotrauma: How do we apply animal experiments to people? Exp. Neurol. 261, 120-126 (2014). doi:10.1016/j.expneurol.2014.07.002

30. Lucke-Wold, B.P., Turner, R.C., Logsdon, A.F., Rosen, C.L., Qaiser, R.: Blast scaling parameters: Transitioning from lung to skull base metrics. J. Surg. Emerg. Med. 1(1), 3 (2017)

31. Jean, A., Nyein, M.K., Zheng, J.Q., Moore, D.F., Joannopoulos, J.D., Radovitzky, R.: An animal-to-human scaling law for blastinduced traumatic brain injury risk assessment. Proc. Natl. Acad. Sci. 111(43), 15310-15315 (2014). doi:10.1073/pnas.1415743111

32. Budde, M.D., Shah, A., McCrea, M., Cullinan, W.E., Pintar, F.A., Stemper, B.D.: Primary blast traumatic brain injury in the rat: Relating diffusion tensor imaging and behavior. Front. Neurol. 4, 154 (2013). doi:10.3389/fneur.2013.00154

33. Turner, R.C., Naser, Z.J., Logsdon, A.F., DiPasquale, K.H., Jackson, G.J., Robson, M.J., Gettens, R.T.T., Matsumoto, R.R., Huber, 
J.D., Rosen, C.L.: Modeling clinically relevant blast parameters based on scaling principles produces functional \& histological deficits in rats. Exp. Neurol. 248, 520-529 (2013). doi:10.1016/ j.expneurol.2013.07.008

34. Huber, B.R., Meabon, J.S., Martin, T.J., Mourad, P.D., Bennett, R., Kraemer, B.C., Cernak, I., Petrie, E.C., Emery, M.J., Swenson, E.R., Mayer, C., Mehic, E., Peskind, E.R., Cook, D.G.: Blast exposure causes early and persistent aberrant phospho- and cleaved-tau expression in a murine model of mild blast-induced traumatic brain injury. J.Alzheimer's Dis. 37(2), 309-323 (2013). doi:10.3233/ JAD- 130182

35. Chavko, M., Koller, W.A., Prusaczyk, W.K., McCarron, R.M.: Measurement of blast wave by a miniature fiber optic pressure transducer in the rat brain. J. Neurosci. Methods 159(2), 277-281 (2007). doi:10.1016/j.jneumeth.2006.07.018

36. Svetlov, S.I., Prima, V., Kirk, D.R., Gutierrez, H., Curley, K.C., Hayes, R.L., Wang, K.K.: Morphologic and biochemical characterization of brain injury in a model of controlled blast overpressure exposure. J. Trauma Acute Care Surg. 69(4), 795-804 (2010). doi:10.1097/TA.0b013e3181bbd885

37. Sundaramurthy, A., Alai, A., Ganpule, S., Holmberg, A., Plougonven, E., Chandra, N.: Blast-induced biomechanical loading of the rat: An experimental and anatomically accurate computational blast injury model. J. Neurotrauma 29(13), 2352-2364 (2012). doi:10.1089/neu.2012.2413

38. Pun, P.B.L., Kan, E.M., Salim, A., Li, Z., Ng, K.C., Moochhala, S.M., Ling, E.-A., Tan, M.H., Lu, J.: Low level primary blast injury in rodent brain. Front. Neurol. 2, 19 (2011). doi:10.3389/fneur. 2011.00019

39. Bolander, R., Mathie, B., Bir, C., Ritzel, D., VandeVord, P.: Skull flexure as a contributing factor in the mechanism of injury in the rat when exposed to a shock wave. Ann. Biomed. Eng. 39(10), 2550-2559 (2011). doi:10.1007/s10439-011-0343-0

40. Cernak, I., Merkle, A.C., Koliatsos, V.E., Bilik, J.M., Luong, Q.T., Mahota, T.M., Xu, L., Slack, N., Windle, D., Ahmed, F.A.: The pathobiology of blast injuries and blast-induced neurotrauma as identified using a new experimental model of injury in mice. Neurobiol. Dis. 41(2), 538-551 (2011). doi:10.1016/j.nbd.2010.10.025

41. VandeVord, P., Bolander, R., Sajja, V., Hay, K., Bir, C.: Mild neurotrauma indicates a range-specific pressure response to low level shock wave exposure. Ann. Biomed. Eng. 40(1), 227-236 (2012). doi:10.1007/s10439-011-0420-4

42. Leonardi, A.D., Bir, C.A., Ritzel, D.V., VandeVord, P.J.: Intracranial pressure increases during exposure to a shock wave. J. Neurotrauma 28(1), 85-94 (2011). doi:10.1089/neu.2010.1324

43. Pham, N., Sawyer, T.W., Wang, Y., Jazii, F.R., Vair, C., Taghibiglou, C.: Primary blast-induced traumatic brain injury in rats leads to increased prion protein in plasma: A potential biomarker for blast-induced traumatic brain injury. J. Neurotrauma 32(1), 58-65 (2015). doi:10.1089/neu.2014.3471

44. Courtney, A., Courtney, M.: The complexity of biomechanics causing primary blast-induced traumatic brain injury: A review of potential mechanisms. Front. Neurol. 6, 221 (2015). doi:10.3389/ fneur.2015.00221

45. Long, J.B., Bentley, T.L., Wessner, K.A., Cerone, C., Sweeney, S., Bauman, R.A.: Blast overpressure in rats: Recreating a battlefield injury in the laboratory. J. Neurotrauma 26(6), 827-840 (2009). doi:10.1089/neu.2008.0748

46. Chandra, N., Ganpule, S., Kleinschmit, N.N., Feng, R., Holmberg, A.D., Sundaramurthy, A., Selvan, V., Alai, A.: Evolution of blast wave profiles in simulated air blasts: Experiment and computational modeling. Shock Waves 22(5), 403-415 (2012). doi:10. 1007/s00193-012-0399-2
47. Ritzel, D.V., Parks, S.A., Roseveare, J., Rude, G., Sawyer, T.W.: Experimental blast simulation for injury studies. NATO HFM 207, Halifax (2011)

48. Sawyer, T.W., Wang, Y., Ritzel, D.V., Josey, T., Villanueva, M., Shei, Y., Nelson, P., Hennes, G., Weiss, T., Vair, C., Fan, C., Barnes, J.: High-fidelity simulation of primary blast: Direct effects on the head. J. Neurotrauma 33(13), 1181-1193 (2016). doi:10.1089/neu. 2015.3914

49. Bailey, Z.S., Grinter, M.B., VandeVord, P.J.: Astrocyte reactivity following blast exposure involves aberrant histone acetylation. Front. Mol. Neurosci. 9, 64 (2016). doi:10.3389/fnmol.2016.00064

50. Long, J.B.: Central mechanisms and treatment of blast induced auditory and vestibular injuries. The Geneva Foundation Tacoma United States, Technical Report 30 (2017)

51. Carr, W., Dell, K.C., Yanagi, M.A., Hassan, D.M., LoPresti, M.L.: Perspectives on repeated low-level blast and the measurement of neurotrauma in humans as an occupational exposure risk. Shock Waves 27(6) (2017). doi:10.1007/s00193-017-0766-0

52. Nakagawa, A., Ohtani, K., Armonda, R., Tomita, H., Sakuma, A., Mugikura, S., Takayama, K., Kushimoto, S., Tominaga, T.: Primary blast-induced traumatic brain injury. Lessons from Lithotripsy. Shock Waves 27(6) (2017). doi:10.1007/s00193-017-0753-5

53. Kamimori, G.H., Reilly, L.A., LaValle, C.R., Olaghere Da Silva, U.B.: Occupational overpressure exposure of breachers and military personnel. Shock Waves 27(6) (2017). doi:10.1007/ s00193-017-0738-4

54. Wiri, S., Ritter, A.C., Bailie, J.M., Needham, C., Duckworth, J.L.: Computational modeling of blast exposure associated with recoilless weapons combat training. Shock Waves 27(6) (2017). doi:10. 1007/s00193-017-0755-3

55. Tripathi, B.B., Espíndola, D., Pinton, G.F.: Piecewise parabolic method for simulating one-dimensional shear shock wave propagation in tissue-mimicking phantoms. Shock Waves 27(6) (2017). doi:10.1007/s00193-017-0734-8

56. Tan, X.G., Przekwas, A.J., Gupta, R.K.: Computational modeling of blast wave interaction with a human body and assessment of traumatic brain injury. Shock Waves 27(6) (2017). doi:10.1007/ s00193-017-0740-x

57. Singh, D., Cronin, D.S.: Efficacy of visor and helmet for blast protection assessed using a computational head model. Shock Waves 27(6) (2017). doi:10.1007/s00193-017-0732-x

58. Sarvghad-Moghaddam, H., Rezaei, A., Ziejewski, M., Karami, G.: Correlative analysis of head kinematics and brain's tissue response: A computational approach toward understanding the mechanisms of blast TBI. Shock Waves 27(6) (2017). doi:10.1007/ s00193-017-0749-1

59. Haniff, S., Taylor, P.A.: In silico investigation of blast-induced intracranial fluid cavitation as it potentially leads to traumatic brain injury. Shock Waves 27(6) (2017). doi:10.1007/ s00193-017-0765-1

60. Kalra, A., Zhu, F., Feng, K., Saif, T., Kallakuri, S., Jin, X., Yang, K., King, A.: Development and validation of a numerical model of the swine head subjected to open field blasts. Shock Waves 27(6) (2017). doi:10.1007/s00193-017-0760-6 